\title{
Cost-reliability analysis of hybrid pumped-battery storage for solar and wind energy integration in an island community.
}

Authors: Fausto A. Canales, Jakub K. Jurasz, Mohammed Guezgouz, Alexandre Beluco

Abstract:

This paper presents a mathematical model for estimating the optimal sizing and assessing a standalone hybrid power system's performance entirely based on variable renewable energy sources and coupled with a hybrid energy storage system. This study evaluates how different levels of the main components' capital cost and the loss of power supply probability would affect the cost of energy and the power system's optimal sizing. The case study selected for this study was Ometepe Island in Nicaragua, where the crater lake of an extinct volcano was considered a feasible upper reservoir of a pumped storage hydropower plant, reducing the investments associated with this component. The mathematical formulation considers energy storage losses and gains, and the Pareto efficient solutions of the multi-objective optimization model simultaneously increase reliability, reduce the cost of energy, and minimize curtailment energy. By employing time-series with an hourly resolution, the model allows assessing the impact of the interannual variability of renewable energy sources on the system's performance. As for the case study, the cost of energy obtained from the model results ranges between $€ 0.047 / \mathrm{kWh}$ and $€ 0.095 / \mathrm{kWh}$, based on international reference values, and these values match the information available in the literature and other databases.

Keywords:

Hybrid power systems, Multi-objective optimization, Hybrid energy storage, Reliability, Energy management strategy

DOI: https://doi.org/10.1016/j.seta.2021.101062 